\title{
MODELING THE PNEUMATIC SUBSYSTEM OF A S-CAM AIR BRAKE SYSTEM
}

A Thesis

by

SHANKAR COIMBATORE SUBRAMANIAN

\author{
Submitted to the Office of Graduate Studies of \\ Texas A\&M University \\ in partial fulfillment of the requirements for the degree of \\ MASTER OF SCIENCE
}

May 2003

Major Subject: Mechanical Engineering 
MODELING THE PNEUMATIC SUBSYSTEM OF A S-CAM AIR BRAKE SYSTEM

\author{
A Thesis \\ by \\ SHANKAR COIMBATORE SUBRAMANIAN
}

Submitted to Texas A\&M University

in partial fulfillment of the requirements

for the degree of

MASTER OF SCIENCE

Approved as to style and content by:

K. R. Rajagopal

(Co-Chair of Committee)

Dvahg Swaroop

(Co-Chair of Committee)

\begin{tabular}{c} 
Jo W. Howze \\
(Member) \\
\hline $\begin{array}{c}\text { John Weese } \\
\text { (Head of Department) }\end{array}$
\end{tabular}

May 2003

Major Subject: Mechanical Engineering 


\begin{abstract}
Modeling the Pneumatic Subsystem of a S-cam Air Brake System. (May 2003)

Shankar Coimbatore Subramanian, B.E., University of Allahabad

Co-Chairs of Advisory Committee: Dr. K. R. Rajagopal

Dr. Dvahg Swaroop
\end{abstract}

The air brake system is one of the critical components in ensuring the safe operation of any commercial vehicle. This work is directed towards the development of a fault-free model of the pneumatic subsystem of the air brake system. This model can be used in brake control and diagnostic applications. Current enforcement inspections are done manually and hence are time consuming and subjective. The long-term objective is to develop a model-based, performance-based diagnostic system that will automate enforcement inspections and help in monitoring the condition of the air brake system. Such a diagnostic system can update the driver on the performance of the brake system during travel and with recent advancements in communication technology, this information can be remotely transferred to the brake inspection teams. Since this system is performance-based, it will eliminate the subjective nature of visual inspections. The first step in the development of such a diagnostic system is to obtain a fault-free model of the air brake system. The model of the pneumatic subsystem correlates the pressure transients in the brake chamber with the brake pedal actuation force and the brake valve plunger displacement. An experimental test bench was set up at Texas A\&M University and the experimental data is used to corroborate the results obtained from the model. 
To my parents Mrs. Jayalakshmi and Mr. C. R. Subramanian 


\section{ACKNOWLEDGMENTS}

I am very fortunate to be a student of Prof. K. R. Rajagopal. It is a great privilege to work under his guidance and I hope I can take full advantage of this opportunity. I thank him for spending his valuable time in guiding and motivating me in this thesis. Next, I express my gratitude to Prof. Darbha Swaroop who helped me all along the way during the course of this project. I thank him for all his weekend lectures on Control Systems and I look forward to learning more from him. I thank Prof. Jo W. Howze for kindly agreeing to be a member of my thesis committee. I am grateful to him for meeting me whenever I needed.

I am very lucky to be in the same office as Dr. Luoyi Tao. I thank him for his valuable suggestions during the course of this project. My special thanks to Dr. J. Murali Krishnan for his valuable help whenever I needed it. His inputs were invaluable while setting up the experimental setup and I thank him for his kindness and generosity. I thank Krishna for his help during the experimental stage and his inputs during the modeling phase. I thank my good friend Parag for his prompt assistance whenever I requested him.

Finally, I am indebted to my parents for their love and blessings. It is due to their never ending support and encouragement that I have been able to reach this position in life. I can never repay them for their sacrifices in bringing me up and allowing me to study in the United States. I feel blessed to have a loving sister, brother-in-law and nephew and I thank them for their love and affection. 


\section{TABLE OF CONTENTS}

CHAPTER Page

I INTRODUCTION $\ldots \ldots \ldots \ldots \ldots$

A. Background ...................... 1

B. Aim and Scope of the Thesis . . . . . . . . . . . . . 4

C. Organization of the Thesis ............ 6

II AN OVERVIEW OF THE AIR BRAKE SYSTEM . . . . . . . . 7

A. The Pneumatic Subsystem . . . . . . . . . . . . . . 7

B. The Mechanical Subsystem . . . . . . . . . . . 7

III THE EXPERIMENTAL SETUP . . . . . . . . . . . . . . 10

IV MODELING THE AIR BRAKE SYSTEM . . . . . . . . . . . 13

A. The Primary Circuit . . . . . . . . . . . . . . . 14

B. The Secondary Circuit . . . . . . . . . . . . . . . . 19

C. Modeling the Fluid Flow . . . . . . . . . . . . . . . 22

V CORROBORATION OF THE MODEL . . . . . . . . . . 35

VI CONCLUDING REMARKS AND FUTURE WORK . . . . . . . . 41

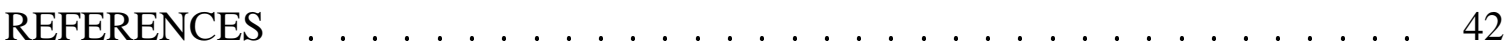

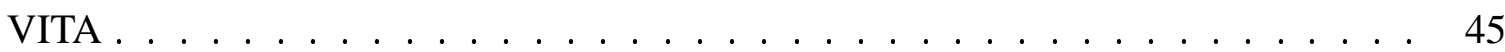




\section{LIST OF TABLES}

TABLE

Page

I Values of the parameters used in the simulation $\ldots \ldots \ldots$ 


\section{LIST OF FIGURES}

FIGURE

Page

1 A general layout of the air brake system in trucks . . . . . . . . 8

2 The mechanical subsystem of a S-cam air brake system . . . . . . . . 8

3 A schematic of a drum brake . . . . . . . . . . . . 9

4 A schematic of the experimental setup . . . . . . . . . . . 11

5 A sectional view of the E-7 dual circuit valve . . . . . . . . . 13

6 The simplified pneumatic system .................. 23

7 The brake chamber as the control volume . . . . . . . . . . . 26

8 A sectional view of the brake chamber . . . . . . . . . . . 29

9 Pressure transients at 60 psig supply pressure - apply phase . . . . . . 35

10 Pressure transients at 80 psig supply pressure - apply phase . . . . . . 37

$11 \quad$ Pressure transients at 90 psig supply pressure - apply phase . . . . . . . 37

$12 \quad$ Pressure transients at 70 psig supply pressure - apply and exhaust phases . 38

13 Pressure transients at 80 psig supply pressure - apply and exhaust phases . 38

$14 \quad$ Pressure transients at 90 psig supply pressure - apply and exhaust phases . 39

15 Pressure transients at 70 psig supply pressure - periodic application . . . . 39 


\section{CHAPTER I}

\section{INTRODUCTION}

\section{A. Background}

The brake system is one of the critical components in ensuring the safety of any vehicle on the road. Most tractor-trailer vehicles with a gross vehicle weight rating over 19,000 $\mathrm{lb}$, most single trucks with a gross vehicle weight rating over 31,000 lb, most transit and inter-city buses, and about half of all school buses are equipped with air brake systems [23]. More than $85 \%$ of the commercial vehicles operating in the United States use S-cam drum foundation brakes in their air brake system [23]. The performance of air brake systems used in commercial vehicles is very sensitive to maintenance procedures such as adjustment of push rod stroke, brake lining replacement, etc. [16]. Malfunctioning brakes are one of the leading mechanical causes of accidents in commercial vehicles. In 1999, among fatal crashes that involved mechanical conditions as a cause, $28.3 \%$ were attributed to defects in the brake system [22]. In roadside inspections performed between 1996 and 1999, 29.3\% of all the vehicle-related violations among Intrastate carriers and 37.2\% of those among Interstate carriers were due to defects in the brake system [7].

Regulations such as the Federal Motor Vehicle Safety Standards (FMVSS) 121 (effective 1973) govern the braking performance of commercial vehicles on roads in the United States. FMVSS 121 specifies a stopping distance criterion and a criterion for lateral vehicle stability, requiring a vehicle to stay within a twelve feet lane when performing a stopping maneuver [21]. Although regular maintenance inspections are carried by truck owners and fleet operators to conform to FMVSS 121, government agencies such as the Office of Motor Carriers conduct enforcement inspections in the interest of public safety. The criteria set

The journal model is IEEE Transactions on Automatic Control. 
by the Commercial Vehicle Safety Alliance (CVSA) guide such enforcement inspections.

Inspection techniques that are used for monitoring the brake system in commercial vehicles can be broadly classified into two categories - visual inspections and performancebased inspections [19]. Visual inspections involve the measurement of the push rod stroke and the thickness of the brake pad lining and checking the brake lines for wear and leaks. Visual inspections are subjective, time and labor intensive and are inconvenient on vehicles with low ground clearance. Performance-based inspections include the measurement of braking force and torque, vehicle deceleration, stopping distance, brake pad temperature etc. Such inspections are more objective and offer a more effective assessment of the condition of the air brake system. Currently, such inspections are required in Europe and are performed only in certified inspection garages [19]. It is appropriate to point out that, in an appraisal of the future needs of the trucking industry [3], the authors, who represent a broad spectrum of the trucking industry, indicate that equipment users would greatly appreciate the development of a standardized, universal, hand-held diagnostic tool. They also stress the need for improvements in the existing inspection techniques and advise the need for the development of performance-based tools that can be used along with visual inspections.

An air brake system differs from a hydraulic brake system used in passenger vehicles in many ways. The most important difference is the mode of operation - in a hydraulic brake system, the pedal force applied by the driver (augmented usually by a vacuum booster) is transmitted through the brake fluid resulting in the application of the foundation brakes on the wheels, whereas, in an air brake system, the application of the treadle valve regulates the air supply from a supply reservoir to the brake chamber. As a result, very little sensory feedback is available to the driver of a commercial vehicle when compared to a vehicle with a hydraulic brake system. Another difference between the two braking systems is in the distribution of the braking force between the various axles. In passenger vehicles, the load 
distribution on the axles varies slightly whereas in commercial vehicles the distribution of the load on the various axles varies significantly depending on whether the vehicle is loaded or unloaded. Typically, commercial vehicle brakes are designed and balanced for the fully loaded condition and this results in excessive braking on some axles when the vehicle is empty [16]. This problem is compounded by the fact that the U.S. regulations, unlike the European standards, does not directly specify brake force distribution between the various axles [17].

In addition to the $\mathrm{S}$-cam foundation brakes, retarders are being used as supplementary braking mechanisms. Compression brakes are commonly used as retarders in current commercial vehicles and they serve to decrease the work load on the foundation brakes thereby increasing the life of the foundation brakes [5]. The main limitation of such retarders is that they can only supplement the friction brakes and can never replace them completely. This is due to the poor torque output characteristics of the retarders at low vehicle speeds and moreover they cannot provide any braking effort when the vehicle is at rest [13].

The hydraulic brake system has been extensively studied and models for the system have been developed by many authors. Gerdes et al. [6] developed a model for a hydraulic brake system with a vacuum booster. They combined a static valve model with equations of air flow within the booster. Khan et al. [9] used bond graph techniques to develop models for the booster, the master cylinder and the wheel cylinder. In both cases, the authors measured the wheel cylinder chamber pressure as a function of time and attempted to predict the pressure transients with their models.

The air brake system used in commercial vehicles is made up of two subsystems - the pneumatic subsystem and the mechanical subsystem. The pneumatic subsystem includes the compressor, the storage reservoirs, the brake lines, the treadle valve and terminates at the brake chamber. The mechanical subsystem starts from the brake chamber and includes the push rod, the slack adjuster, the S-cam and the brake pads. Thus, it can be seen that de- 
veloping a model for the air brake system is a complicated process due to the large number of components involved. The majority of the published work on air brake systems relate brake force, vehicle deceleration, brake pad temperature and brake torque as a function of brake chamber pressure and push rod stroke [8], [15], [18], [20]. In all the experiments, the brake chamber pressure was measured for each application and was correlated with other measurements such as those mentioned above. This is essentially an indication of the characteristics of the mechanical subsystem of the air brake system.

A model for the pneumatic subsystem must be able to predict the pressure transients in the brake chamber as a function of the supply pressure from the reservoir and the pedal force applied by the driver. More recently, Acarman et al. [1] suggested a model to predict the growth of air pressure in the brake chamber of a brake system equipped with an Antilock Braking System (ABS). They used orifice flow equations to model the dynamics of air flow and included the dynamics of a modulator located downstream from the treadle valve. The modulator regulates the pressure of air in the brake chamber depending on the mode of operation as decided by the ABS controller.

\section{B. Aim and Scope of the Thesis}

The aim in this thesis is to develop a model that can predict the pressure transients over a wide range of supply pressures and also at partial brake applications. Such a model is highly desirable since, according to [12], almost $97 \%$ of typical service brake applications in commercial vehicles are made below 30 psig. The pneumatic subsystem is modeled so that the pressure transients in the brake chamber can be predicted from the measurements of the pedal force and pedal displacement. The dynamics of the treadle valve is incorporated into the model and the treadle valve is treated as a nozzle. The reason behind this choice is explained in Chapter (IV). 
Certain assumptions have been made in the development of the model. A lumped parameter approach is adopted in modeling both the mechanical components of the valve and the flow of air in the system. The viscosity of air has been neglected and it is assumed to behave like an ideal gas. The expansion process in the valve is assumed to be isentropic and a coefficient of discharge used to account for the losses during expansion. It is also assumed that the flow from the valve to the brake chamber be adiabatic. All the above assumptions are approximations to the real process and the choice of these approximations is supported by the fact that the results from the model developed under these assumptions agree well with the experimental data as will be seen later in Chapter (V).

The long-term aim is to develop an on-board, model-based, performance-based diagnostic tool that can be used in inspecting the air brake system. Such a diagnostic tool can frequently update the driver on the performance of the brake system during travel. With recent advancements in communication technology, it is also possible to transfer the diagnostic information remotely to the roadside inspection teams which will reduce the inspection time significantly. This is desirable since, according to [11], the average time required for a typical roadside inspection is around 30 minutes, with approximately half of the time spent on brakes. Since the diagnostic system is performance-based, it will eliminate the subjective nature of visual inspections.

The first step in the development of such a diagnostic tool is the development of a fault-free model of the air brake system. In this thesis, we deal with the modeling of the pneumatic subsystem of the air brake system. The results from the model will be corroborated with the data obtained from the experiments for various test runs. Once a model is developed for the pneumatic subsystem, it can be combined with a model for the mechanical subsystem to obtain a complete model of the air brake system. A fault-free model of the air brake system will be able to predict the brake chamber pressure, the push rod stroke, the brake torque and the wheel speed from measurements of the brake valve 
plunger displacement and the brake pedal actuation force. Thus, a fault-free model gives a correlation between the above mentioned variables under normal operating conditions. The use of this fault-free model in the diagnostic system will help in detecting failures in the air brake system whenever they occur.

\section{Organization of the Thesis}

Chapter II presents a description of the pneumatic and the mechanical subsystems of the air brake system. Chapter III outlines the details of the experimental test bench set up at Texas A\&M University. Information regarding the various transducers and the Data Acquisition (DAQ) system used is also given in this chapter. Chapter IV presents a detailed description of the model of the pneumatic subsystem. The equations governing the motion of the various components of the valve are derived followed by the equations describing the flow of air in the system. In Chapter V we look at the results obtained from the simulation of the model for various test runs. These results are corroborated with the experimental data collected for each test run. Chapter VI provides a summary of results and scope for future work. 


\section{CHAPTER II}

\section{AN OVERVIEW OF THE AIR BRAKE SYSTEM}

\section{A. The Pneumatic Subsystem}

A general layout of the pneumatic subsystem in the air brake system of a tractor-trailer is shown in Fig. 1. The compressor charges up the storage reservoirs and the application of the treadle valve modulates the amount of air provided to the brake chambers. Compressed air is supplied from the treadle valve to the various brake chambers through two circuits - the primary circuit and the secondary circuit. The advantage of such an arrangement is that partial braking is possible in the case of failure of one of the two circuits, though the complexity of the system is increased. In trucks, the primary circuit provides compressed air to the rear brakes and the secondary circuit operates the front brakes. Since 1968, federal standards have warranted the use of dual-circuit valve brake systems in cars and other passenger vehicles and since the mid-1970's this was extended to include commercial vehicles with air brake systems [4]. FMVSS 121 spells out the performance standards required for air brake systems and FMVSS 105 provides the standards for hydraulic brake systems.

\section{B. The Mechanical Subsystem}

The mechanical subsystem of the S-cam air brake system is illustrated in Fig. 2. Compressed air acts on the brake chamber diaphragm providing a mechanical force that is transmitted to the brake pads through the push rod and the S-cam. The force output from the push rod to the brake pads decreases rapidly when its stroke exceeds a certain limit [20]. The stroke of the push rod increases due to the wear of the brake linings and also due to the expansion of the brake drum as a consequence of the heat generated during braking. 


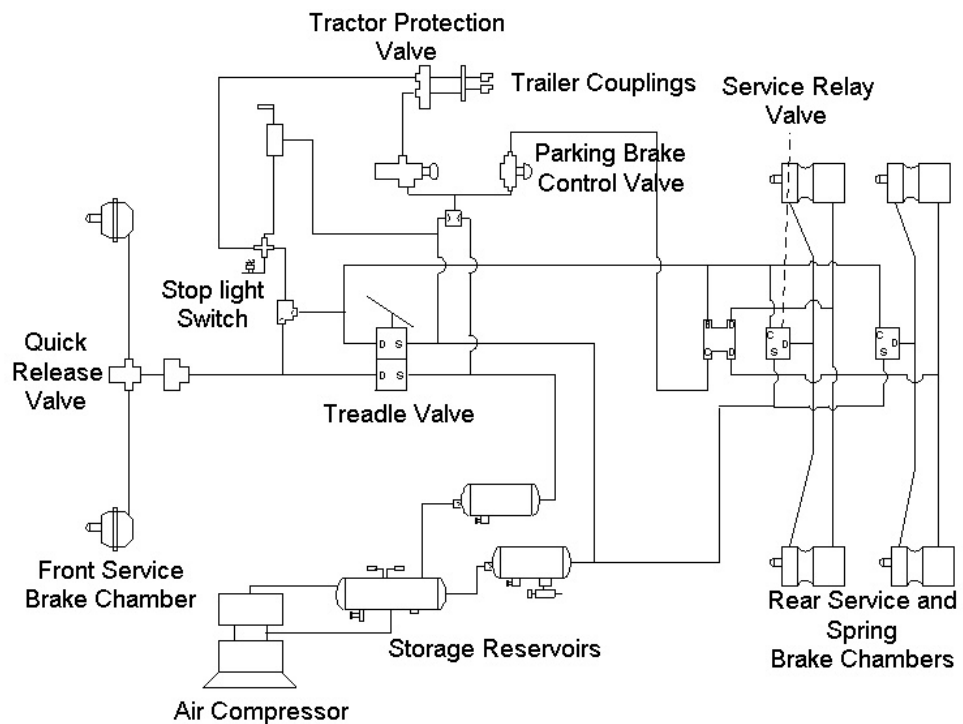

Fig. 1. A general layout of the air brake system in trucks

Automatic slack adjusters are used to compensate for this increase in stroke.

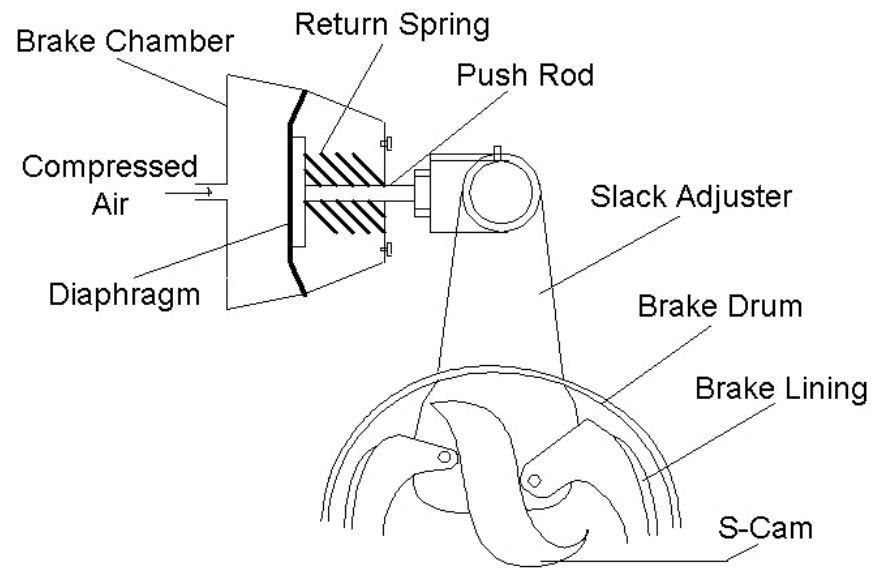

Fig. 2. The mechanical subsystem of a S-cam air brake system

Drum brakes (see Fig. 3) are the most common foundation brakes found in commercial vehicles in the United States, whereas in Europe disc brakes are slowly replacing drum brakes over the past decade [4]. Disc brakes offer lower sensitivity of the brake torque to 
the brake pad friction coefficient, better fade resistance and improved brake efficiency when compared to drum brakes. Their main limitation is the absence of "self-energization" [4] (this term refers to the augmentation of the moment due to the actuation force acting on the brake pad by the moment due to the friction force acting on the brake pad) available in drum brakes resulting in the need for higher actuation air pressures when compared to drum brakes.

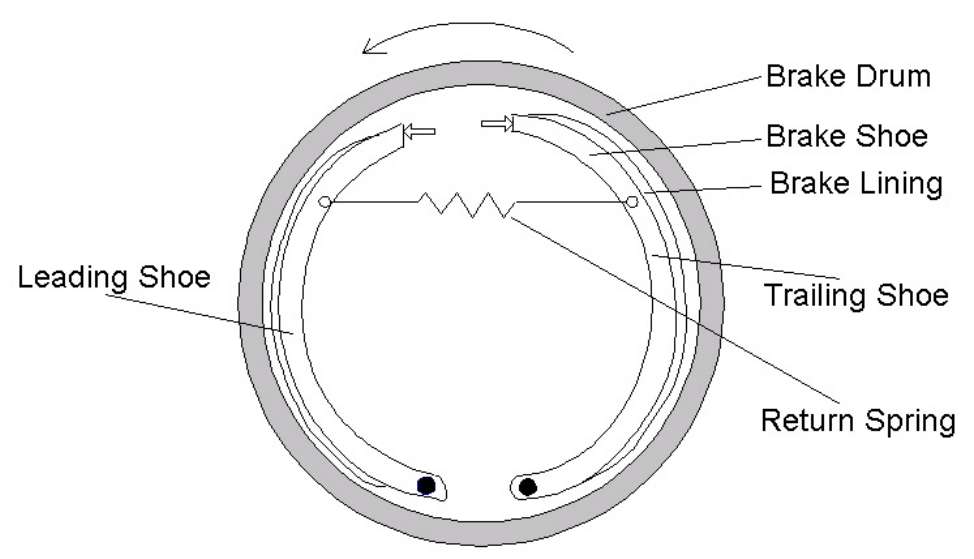

Fig. 3. A schematic of a drum brake 


\section{CHAPTER III}

\section{THE EXPERIMENTAL SETUP}

The experimental test bench at Texas A\&M University is essentially the front axle of a tractor. Compressed air is provided by a Campbell Hausfeld oil-less compressor which has a maximum pressure rating of 120 psi. It has a six gallon storage tank with a dial gage indicating the pressure of the compressed air stored in the tank. A drain cock, located at the bottom of the storage tank, is used to periodically remove the moisture accumulated in the tank. The compressor is powered electrically and a pressure switch shuts it down when the pressure in the tank reaches 120 psi and turns it on when the pressure drops down to around 105 psi. A pressure regulator (Manufacturer - Omega Engineering, Model Number PRG501-120) is provided to modulate the pressure of the air being supplied to the treadle valve. Fig. 4 shows a schematic of the experimental setup.

The treadle valve used is the E-7 dual circuit valve manufactured by Allied Signals/Bendix (see Fig. 5). The primary circuit is actuated by the pedal force and the secondary circuit acts essentially as a relay valve. Under normal operating conditions, air bled off from the primary delivery is used to actuate a relay piston which in turn actuates the secondary circuit. When the primary circuit fails, the secondary circuit is actuated directly by pedal force. When the brake pedal is applied, the primary piston first closes the primary exhaust and then opens the primary inlet valve. This is the apply phase. When the delivery pressure increases to a level where it balances the pedal input force, the primary inlet valve is closed with the primary exhaust also remaining closed. This is the balance or the hold phase. When the pedal is released, so is the balancing force on the primary piston, which causes the primary piston to lift off from the primary exhaust seat and the air in the delivery circuit is exhausted to the atmosphere thereby releasing the brakes. This is the exhaust phase. The secondary circuit functions in a similar manner except for the fact that the relay 
piston is used to actuate it under normal operating conditions.

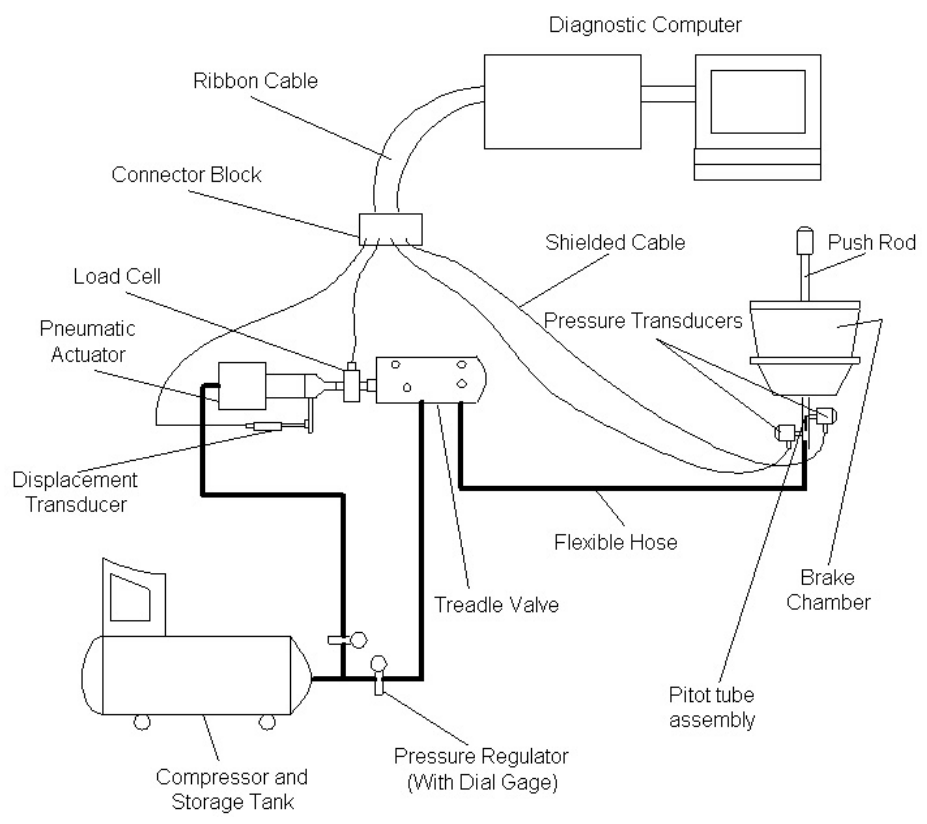

Fig. 4. A schematic of the experimental setup

The compressed air from the treadle valve is supplied to the brake chamber through brake hoses. A pneumatic actuator is used to apply the treadle valve. The air supply to the pneumatic actuator is provided from the storage tank through a pressure regulator similar to the one used for regulating the supply pressure to the treadle valve. The brake chamber is a "Type-20" brake chamber, i.e., it has a cross-sectional area of $20 \mathrm{in}^{2}$. The stroke of the push rod rotates the S-cam through the automatic slack adjuster. The rotation of the S-cam in turn pushes the brake shoes against the brake drum.

The axial displacement of the treadle valve is measured with a linear potentiometer having a maximum stroke of $3^{\prime \prime}$ (Manufacturer - Omega Engineering, Model Number LP802-75). An input excitation of $5 \mathrm{~V}$ d.c. is provided to the potentiometer by a power source (Manufacturer - Omega Engineering, Model Number PSS-5A). The potentiometer 
has been calibrated and it is found to be sufficiently linear in the range of interest. A load cell (Manufacturer - Omega Engineering, Model Number LC203-1K) is mounted between the actuating shaft of the pneumatic actuator and the plunger on the brake pedal. It is excited by a $10 \mathrm{~V}$ d.c. power supply (Manufacturer - Omega Engineering, Model Number DMD-465WB) and has a full scale output of $20 \mathrm{mV}$. This output is amplified through an amplifier which is built in the power supply of the load cell. A pitot tube assembly was specially fabricated and calibrated in order to measure the Mach numbers in the flow at the entrance of the brake chamber. The pitot tube was mounted at the entrance of the brake chamber and two pressure transducers were used to measure the static and the stagnation pressures. The pressure transducer (Manufacturer - Omega engineering, Model Number PX181-100G5V) has a range of 0-100 psig. An excitation of $24 \mathrm{~V}$ d.c. is provided to the pressure transducer by a power supply (Manufacturer - Omega Engineering, Model Number U24Y101) and the voltage output of the transducer is from 1 to $5 \mathrm{~V}$ d.c. The pressure transducer has a response time of less than 5 milliseconds. The transducers are interfaced with a connector block through shielded cables. Data is collected through a PCI-1200 Data Acquisition (DAQ) board (Manufacturer - National Instruments) and the connector block is interfaced with the DAQ board via a ribbon cable. An application program written in MATLAB records all the collected data and plots it. A low-pass digital filter [14], with a cut-off frequency of $20 \mathrm{~Hz}$., is used to filter the collected data. 


\section{CHAPTER IV}

\section{MODELING THE AIR BRAKE SYSTEM}

A lumped parameter approach has been adopted in modeling the pneumatic subsystem of the air brake system. A model for the pneumatic subsystem of the air brake system must take into consideration the dynamics of the treadle valve and the flow of air in the system. A sectional view of the the E-7 dual circuit valve is shown in Fig. 5. We will now derive the equations of motion of the components of the treadle valve.

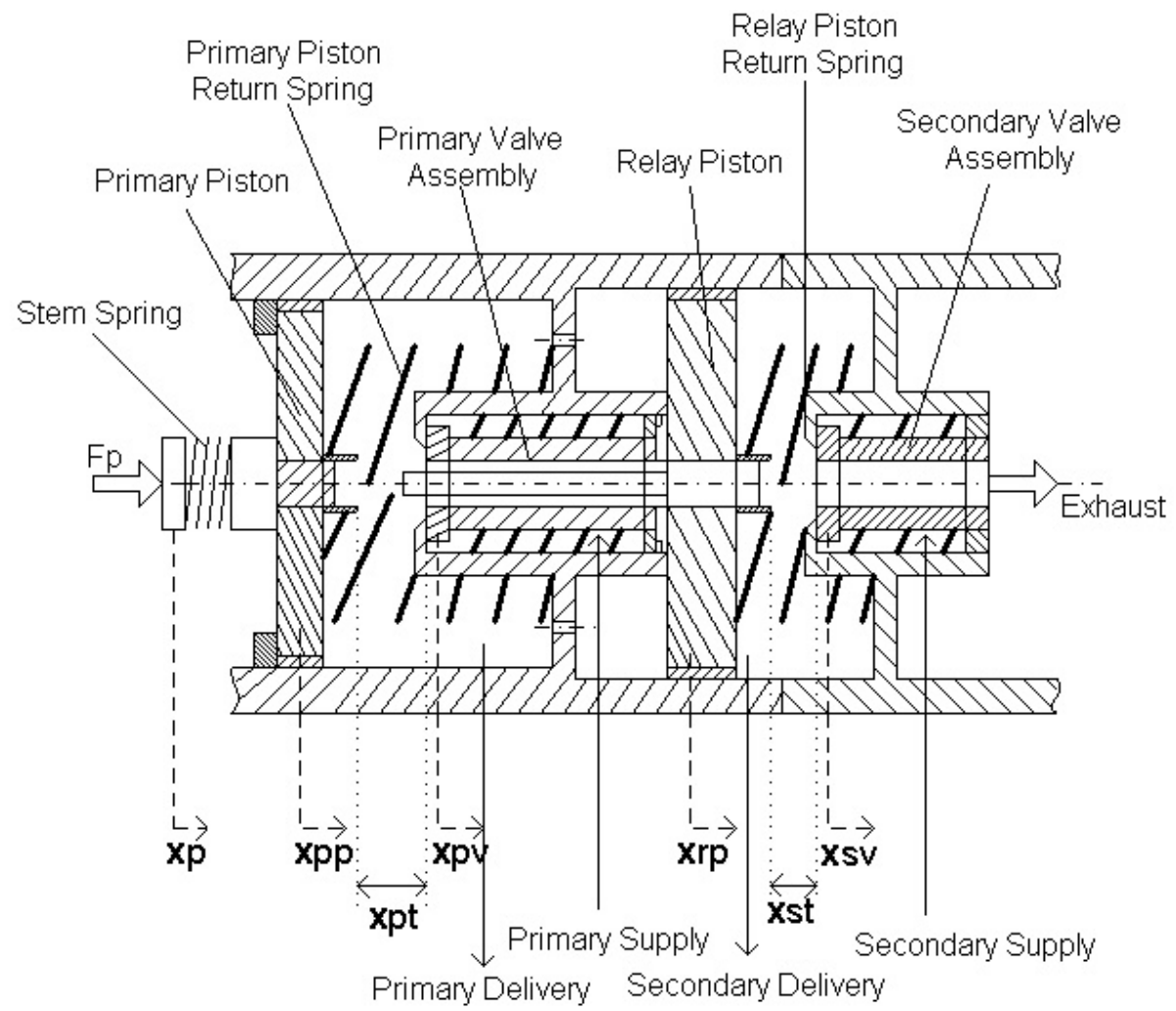

Fig. 5. A sectional view of the E-7 dual circuit valve

Let $F_{p}$ denote the force input to the valve plunger. Let $x_{p}$ denote the axial displacement of the plunger from its initial position. Let $x_{p p}$ and $x_{p v}$ denote the displacement of the pri- 
mary piston and the primary valve assembly gasket from their initial positions respectively. Let $x_{p t}$ denote the distance traveled by the primary piston before it closes the primary exhaust. Let $K_{s s}, K_{p p}$ and $K_{p v}$ denote the spring constants of the stem spring, primary piston return spring and the primary valve assembly return spring respectively. Let $x_{r p}$ and $x_{S v}$ denote the displacement of the relay piston and the secondary valve assembly gasket from their initial positions respectively. Let $x_{s t}$ denote the distance traveled by the relay piston before it closes the secondary exhaust. Let $K_{r p}$ and $K_{s v}$ denote the spring constants of the relay piston return spring and the secondary valve assembly return spring respectively.

We assume the friction at the sliding surfaces to be negligible. This is reasonable since the sliding surfaces are lubricated with grease. The springs in the treadle valve were tested and found to be linear in the region of their operation. Thus, the springs can be described by the constitutive equation, $F=K x$, where $F$ is the net force applied on the spring, $x$ is the deflection of the spring from its initial position and $K$ is the spring constant. The spring constants and the initial pre-loads on the springs were measured and used in the model. Geometric parameters such as areas, initial deflections, etc. were also measured and used in the following equations.

\section{A. The Primary Circuit}

We model the primary circuit for its different phases of operation. The equation of motion of the primary piston till it closes the exhaust port can be written as,

$$
M_{p p}\left(\frac{d^{2} x_{p p}}{d t^{2}}\right)=F_{p}-K_{s s}\left(x_{p p}-x_{p}\right)-K_{p p} x_{p p}-F_{k p p i}
$$

where $M_{p p}$ is the mass of the primary piston and $F_{k p p i}$ is the initial pre-load on the primary piston return spring. 
The equation of motion of the primary piston during the apply and hold phases can be written as,

$$
M_{p p}\left(\frac{d^{2} x_{p p}}{d t^{2}}\right)=F_{p}-K_{s s}\left(x_{p p}-x_{p}\right)-K_{p p} x_{p p}-F_{k p p i}-F_{p p}-F_{\text {reacn }}^{p 1}-F_{\text {reacn }}^{p 2}
$$

where $F_{p p}$ is the net pressure force acting on the primary piston, $F_{\text {reacn }}^{p 1}$ is the reaction force applied by the primary valve assembly gasket on the primary piston and $F_{\text {reacn }}^{p 2}$ is the reaction force applied by the relay piston stem on the primary piston.

The equation of motion of the primary valve assembly gasket during the apply and hold phases can be written as,

$$
M_{p v}\left(\frac{d^{2} x_{p v}}{d t^{2}}\right)=F_{r e a c n}^{p 1}-K_{p v} x_{p v}-F_{k p v i}-F_{p v}
$$

where $M_{p v}$ is the mass of the primary valve assembly gasket, $F_{k p v i}$ is the initial pre-load on the primary valve assembly return spring and $F_{p v}$ is the net pressure force acting on the primary valve assembly gasket.

Adding equations (4.2) and (4.3) and re-arranging the terms results in,

$$
\begin{array}{r}
M_{p p}\left(\frac{d^{2} x_{p p}}{d t^{2}}\right)+\left(K_{s s}+K_{p p}\right) x_{p p}+M_{p v}\left(\frac{d^{2} x_{p v}}{d t^{2}}\right)+K_{p v} x_{p v} \\
=K_{s s} x_{p}+F_{p}-F_{k p p i}-F_{k p v i}-F_{p p}-F_{p v}-F_{\text {reacn }}^{p 2}
\end{array}
$$

The three stages of operation of the primary circuit can be described by the following relations:

- Apply Phase

$$
x_{p p}>x_{p t}
$$


- Hold Phase

$$
x_{p p}=x_{p t}
$$

- Exhaust Phase

$$
x_{p p}<x_{p t}
$$

Now, at any instant of time during the apply and hold phases,

$$
x_{p v}(t)=x_{p p}(t)-x_{p t}
$$

Making use of equation (4.8), we can rewrite equation (4.4) as the following,

$$
\begin{array}{r}
\left(M_{p p}+M_{p v}\right)\left(\frac{d^{2} x_{p p}}{d t^{2}}\right)+\left(K_{s s}+K_{p p}+K_{p v}\right) x_{p p}-K_{p v} x_{p t} \\
=K_{s s} x_{p}+F_{p}-F_{k p p i}-F_{k p v i}-F_{p p}-F_{p v}-F_{r e a c n}^{p 2}
\end{array}
$$

We note that the three terms $K_{p v} x_{p t}, F_{k p p i}$ and $F_{k p v i}$ are independent of time and hence combine them as a single constant $F_{1}$ given by,

$$
F_{1}=K_{p v} x_{p t}-F_{k p p i}-F_{k p v i}
$$

Next, we define the constant $K_{2}$ as,

$$
K_{2}=K_{s s}+K_{p p}+K_{p v}
$$

Now, let us look at the term $F_{p p}$, which is the pressure force acting on the primary piston due to the primary delivery air. Let $A_{p p}$ be the net area of the primary piston exposed to the delivered pressurized air. Assuming the pressure to be uniform over the surface of the primary piston, the term $F_{p p}$ can be written as,

$$
F_{p p}=\left(P_{p d}-P_{a t m}\right) A_{p p}
$$

where $P_{p d}$ is the pressure of the primary delivery air at any instant of time and $P_{a t m}$ is the 
atmospheric pressure (all the pressure terms used here represent absolute pressures).

Next, let us consider the term $F_{p v}$, which is the net pressure force acting on the primary valve assembly gasket. Let $A_{p v 1}$ and $A_{p v}$ be the net cross-sectional area of the primary valve assembly gasket exposed to the pressurized air at the supply and the delivery respectively. Under the same assumptions as above and also assuming the gasket to be sufficiently rigid (which is reasonable since the gasket is enclosed by a metal ring), we can write the expression for $F_{p v}$ as,

$$
F_{p v}=P_{p s} A_{p v 1}-P_{p d} A_{p v}
$$

where $P_{p s}$ is the supply air pressure to the primary circuit.

Using equations (4.10) to (4.13), equation (4.9) can be now written as,

$$
\begin{array}{r}
\left(M_{p p}+M_{p v}\right)\left(\frac{d^{2} x_{p p}}{d t^{2}}\right)+K_{2} x_{p p}=K_{s s} x_{p}+F_{p} \\
+F_{1}-P_{p d}\left(A_{p p}-A_{p v}\right)-P_{p s} A_{p v 1}-F_{r e a c n}^{p 2}+P_{a t m} A_{p p}
\end{array}
$$

Equation (4.14) represents the dynamics of the primary circuit during the apply and hold phases. We now assume the inertia of the primary piston and the primary valve assembly gasket to be small compared to the other forces. With this assumption, the above equation reduces to the following,

$$
K_{2} x_{p p}=K_{s s} x_{p}+F_{p}+F_{1}-P_{p d}\left(A_{p p}-A_{p v}\right)-P_{p s} A_{p v 1}-F_{r e a c n}^{p 2}+P_{a t m} A_{p p}
$$

This equation is used with equation (4.65), which will be derived in section (C) of this chapter, to obtain the response of the primary circuit to various pedal inputs. The term $F_{\text {reacn }}^{p 2}$ is obtained from equation (4.20), which will be derived in the following section. It should be noted that this term will be present in the above equation only till the primary piston and the primary valve assembly are in contact with the relay piston. At some point 
during the apply phase, this contact would be broken and then this term would be set to zero.

Next, we look at the equation of motion of the primary piston during the exhaust phase. During the exhaust phase, the primary piston would break off from the primary valve assembly gasket and thus uncovers the exhaust port. We define $x_{p p e}$ and $x_{p e}$ as the displacement of the primary piston and the treadle valve plunger from their equilibrium positions at the start of the exhaust phase respectively. The equation of motion of the primary piston in this case can be written as,

$$
M_{p p}\left(\frac{d^{2} x_{p p e}}{d t^{2}}\right)=F_{p p}-F_{p}-K_{s s}\left(x_{p p e}-x_{p e}\right)-K_{p p} x_{p p e}+F_{k p p i e}
$$

where $F_{\text {kppie }}$ is the pre-load on the primary piston return spring at the start of the exhaust phase. Neglecting the inertia of the primary piston and using equation (4.12), the above equation can be simplified as,

$$
L_{2} x_{p p e}=K_{s s} x_{p e}-F_{p}+L_{1}+P_{p d} A_{p p}-P_{a t m} A_{p p}
$$

where we define $L_{1}$ and $L_{2}$ in the following way:

$$
\begin{gathered}
L_{1}=F_{k p p i e} \\
L_{2}=K_{s s}+K_{p p}
\end{gathered}
$$

Equation (4.17) governs the motion of the primary piston during the exhaust phase. This equation is used along with the equation governing the fluid flow developed in section (C) of this chapter to obtain the pressure transients in the primary circuit during the exhaust phase. 


\section{B. The Secondary Circuit}

We now model the secondary circuit of the treadle valve for its various phases of operation. The equation of motion of the relay piston till it closes the exhaust port is given by,

$$
M_{r p}\left(\frac{d^{2} x_{r p}}{d t^{2}}\right)=F_{r e a c n}^{p 2}+F_{r p d}-K_{r p} x_{r p}-F_{k r p i}-P_{a t m} A_{r p}^{\prime}
$$

where $M_{r p}$ is the mass of the relay piston, $F_{\text {reacn }}^{p 2}$ is the net mechanical force transmitted by the primary circuit to the relay piston, $F_{r p d}$ is the pressure force acting on the relay piston due to the air bled from the primary delivery, $F_{k r p i}$ is the initial pre-load on the relay piston return spring and $A_{r p}^{\prime}$ is the net area of the relay piston exposed to the secondary delivery air.

During the apply and hold phases of the secondary circuit, the equation of motion for the relay piston is,

$$
M_{r p}\left(\frac{d^{2} x_{r p}}{d t^{2}}\right)=F_{r e a c n}^{p 2}+F_{r p d}-K_{r p} x_{r p}-F_{k r p i}-F_{s p}-F_{r e a c n}^{s}
$$

where $F_{s p}$ is the net pressure force acting on the relay piston as a result of the increasing secondary delivery pressure and $F_{\text {reacn }}^{s}$ is the reaction force exerted by the secondary valve assembly gasket on the relay piston.

The equation of motion for the secondary valve assembly gasket during the apply and hold phases can be written as,

$$
M_{s v}\left(\frac{d^{2} x_{s v}}{d t^{2}}\right)=F_{r e a c n}^{s}-K_{s v} x_{s v}-F_{k s v i}-F_{s v}
$$

where $M_{s v}$ is the mass of the secondary valve assembly gasket, $F_{k s v i}$ is the initial pre-load on the secondary valve assembly return spring and $F_{s v}$ is the net pressure force acting on the secondary valve assembly gasket. 
Adding equations (4.21) and (4.22), we obtain,

$$
\begin{aligned}
M_{r p}\left(\frac{d^{2} x_{r p}}{d t^{2}}\right)+M_{s v} & \left(\frac{d^{2} x_{s v}}{d t^{2}}\right)=F_{r e a c n}^{p 2}+F_{r p d}-K_{r p} x_{r p} \\
& -F_{k r p i}-F_{s p}-K_{s v} x_{s v}-F_{k s v i}-F_{s v}
\end{aligned}
$$

The three stages of operation of the secondary circuit can be described by the following relations:

- Apply Phase

$$
x_{r p}>x_{s t}
$$

- Hold Phase

$$
x_{r p}=x_{s t}
$$

- Exhaust Phase

$$
x_{r p}<x_{s t}
$$

Next, we note that at any instant of time during the apply and hold phases,

$$
x_{s v}(t)=x_{r p}(t)-x_{s t}
$$

Using equation (4.27), equation (4.23) can be rewritten as,

$$
\begin{array}{r}
\left(M_{r p}+M_{s v}\right)\left(\frac{d^{2} x_{r p}}{d t^{2}}\right)+\left(K_{r p}+K_{s v}\right) x_{r p}-K_{s v} x_{s t}= \\
F_{\text {reacn }}^{p^{2}}+F_{r p d}-F_{s p}-F_{s v}-F_{k r p i}-F_{k s v i}
\end{array}
$$

We note that the three terms $K_{s v} x_{s t}, F_{k r p i}$ and $F_{k s v i}$ are independent of time and hence combine them as a single constant $F_{3}$ given by,

$$
F_{3}=K_{s v} x_{s t}-F_{k r p i}-F_{k s v i}
$$


Next, we define the constant $K_{4}$ as,

$$
K_{4}=K_{r p}+K_{s v}
$$

Next, the term $F_{r p d}$ can be expressed as,

$$
F_{r p d}=P_{p d} A_{r p}
$$

where $P_{p d}$ is the primary delivery air pressure and $A_{r p}$ is the area of the relay piston exposed to the primary delivery air.

Now, the net pressure force, $F_{s p}$, acting on the relay piston due to the secondary delivery air can be written as,

$$
F_{s p}=P_{s d} A_{r p}^{\prime}
$$

where $P_{s d}$ is the secondary delivery air pressure.

Next, the net pressure force, $F_{s v}$, acting on the secondary valve gasket can be expressed as,

$$
F_{s v}=\left(P_{s s}-P_{s d}\right) A_{s v}
$$

where $P_{s s}$ is the secondary supply air pressure and $A_{s v}$ is the area of the gasket exposed to the pressurized air.

Using equations (4.29) to (4.33), equation (4.28) can be rewritten as,

$$
\left(M_{r p}+M_{s v}\right)\left(\frac{d^{2} x_{r p}}{d t^{2}}\right)+K_{4} x_{r p}=F_{r e a c n}^{p 2}+P_{p d} A_{r p}-P_{s d}\left(A_{r p}^{\prime}-A_{s v}\right)-P_{s s} A_{s v}+F_{3}
$$

Equation (4.34) represents the dynamics of the secondary circuit during the apply and hold phases. Next, we assume the inertia of the relay piston and the secondary valve assembly gasket to be small compared to the other forces. Then, the above equation reduces to, 


$$
K_{4} x_{r p}=F_{r e a c n}^{p 2}+P_{p d} A_{r p}-P_{s d}\left(A_{r p}^{\prime}-A_{s v}\right)-P_{s s} A_{s v}+F_{3}
$$

This equation is used with equation (4.65) to obtain the response of the secondary circuit to various pedal inputs.

Next, we look at the equation of motion of the relay piston during the exhaust phase. During the exhaust phase, the relay piston uncovers the secondary exhaust port. We define $x_{r p e}$ as the displacement of the relay piston from its equilibrium position at the start of the exhaust phase. The equation of motion of the relay piston in this case can be written as,

$$
M_{r p}\left(\frac{d^{2} x_{r p e}}{d t^{2}}\right)=F_{s p}+F_{k r p i e}-K_{r p} x_{r p e}-F_{r e a c n}^{p 2}-F_{r p d}
$$

where $F_{k r p i e}$ is the load on the relay piston return spring at the start of the exhaust phase. Neglecting the inertia of the relay piston and using equations (4.31) and (4.32), the above equation is simplified as,

$$
K_{r p} x_{r p e}=P_{s d} A_{r p}^{\prime}+F_{k r p i e}-P_{p d} A_{r p}-F_{r e a c n}^{p 2}
$$

Equation (4.37) governs the motion of the relay piston during the exhaust phase. It is used along with the equation governing the fluid flow developed in section (C) of this chapter to obtain the pressure transients in the secondary circuit during the exhaust phase.

\section{Modeling the Fluid Flow}

We idealize the treadle valve as a nozzle. For the flow through a restriction, if the ratio of the cross-sectional area of the upstream section to the cross-sectional area of the restriction is more than around 4.4 , the approach velocity to this restriction can be neglected and the upstream static properties (such as pressure, enthalpy, temperature, etc.) can be taken to be the upstream total or stagnation properties [2]. In our case, the minimum ratio of the 
cross-sectional area of the supply chamber of the valve to the cross-sectional area of the valve opening (the restriction in our case) was found out to be around 15.4. Also, the crosssectional area of the valve opening decreases monotonically to a minimum value. Hence, we can consider the valve opening as a nozzle and take the static properties in the supply chamber of the valve as the stagnation properties at the inlet section of the nozzle. The flow through this idealized valve is assumed to be one-dimensional and isentropic. Further, the fluid properties are assumed to be uniform at all sections in the nozzle. We assume air to behave like an ideal gas. Fig. 6 shows the simplified pneumatic system under the above assumptions.

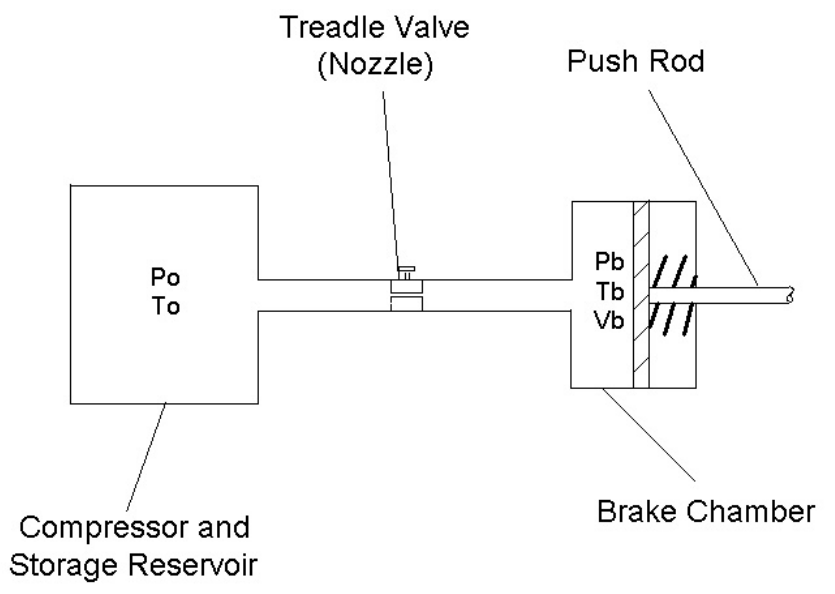

Fig. 6. The simplified pneumatic system

The energy equation for isentropic flow of air through the nozzle under the above assumptions can be written as [10],

$$
h+\frac{1}{2} u^{2}=h_{o}
$$

where $h_{o}$ is the specific stagnation enthalpy at the entrance section of the nozzle, $h$ is the specific static enthalpy at the exit section of the nozzle and $u$ is the velocity of air at the exit section of the nozzle. 
Since air is considered to be an ideal gas, its specific enthalpy at any point in the flow region can be written as,

$$
h=c_{p} T
$$

where $c_{p}$ is the specific heat of air at constant pressure (assumed to be a constant) and $T$ is the local static temperature of the air at that point. Then, equation (4.38) can be rewritten as,

$$
c_{p} T+\frac{1}{2} u^{2}=c_{p} T_{o}
$$

where $T_{o}$ is the stagnation temperature of the compressed air in the supply chamber.

We have made the assumption that air behaves like an ideal gas. For an ideal gas, the local static pressure is a function only of its local density, i.e.,

$$
P=P(\rho)
$$

where $P$ is the local static pressure and $\rho$ is the local density of air.

We use the following "Ideal Gas Law" in the equations below:

$$
P(\rho)=\rho R T
$$

where $R$ is the gas constant for air and $T$ is the local static temperature.

For isentropic flow of an ideal gas, the static pressure, density and static temperature are related by,

$$
\begin{gathered}
\frac{P}{\rho^{\gamma}}=\text { constant } \\
\left(\frac{P^{\left(\frac{\gamma-1}{\gamma}\right)}}{T}\right)=\text { constant }
\end{gathered}
$$


where $\gamma$ is the ratio of the specific heats. We assume that this ratio is a constant.

$$
\gamma=\frac{c_{p}}{c_{v}}
$$

where $c_{v}$ is the specific heat of air at constant volume.

For an ideal gas, the two specific heats are related by,

$$
c_{p}-c_{v}=R
$$

Thus, from (4.45) and (4.46),

$$
\begin{gathered}
c_{p}=\left(\frac{\gamma}{\gamma-1}\right) R \\
c_{v}=\left(\frac{1}{\gamma-1}\right) R
\end{gathered}
$$

Using equations (4.42) to (4.47), equation (4.40) can be solved for the velocity $u$ as,

$$
u=\left(\left(\frac{2 \gamma}{\gamma-1}\right) \frac{P_{o}}{\rho_{o}}\left[1-\left(\frac{P}{P_{o}}\right)^{\left(\frac{\gamma-1}{\gamma}\right)}\right]\right)^{\frac{1}{2}}
$$

Next, we choose the brake chamber and the air hose as the control volume under consideration. We assume all fluid properties in the control volume to be uniform at any instant of time. We assume frictional losses in the hose to be negligible. The Mach number of the flow in the hose was measured at the entrance of the brake chamber. The following formula from [10] is used to calculate the Mach number from the measurements of the static and stagnation pressures.

$$
M=\left(\left(\frac{2}{\gamma-1}\right)\left(\left(\frac{P_{o}}{P}\right)^{\left(\frac{\gamma-1}{\gamma}\right)}-1\right)\right)^{\frac{1}{2}}
$$

where $M$ is the local Mach number and $P_{o}$ is the local stagnation pressure. Although the 
above formula for the Mach number does not really hold for the problem under consideration, we proceed to use this approximation in the development of this model. For various test runs, the value of the Mach number was found not to exceed 0.2. Hence, we can neglect the effects of compressibility of air for the flow through the hose [24]. Applying mass balance to the control volume (see Fig. 7), we obtain,

$$
\dot{m}_{b}=\rho u A_{p}
$$

where $\dot{m}_{b}$ is the rate of change of the mass of air in the control volume, $\rho$ is the density of air inside the control volume at any instant of time, $u$ is the velocity of air at the exit section of the nozzle. This is the velocity of air entering the control volume and $A_{p}$ is the cross-sectional area of the valve opening.

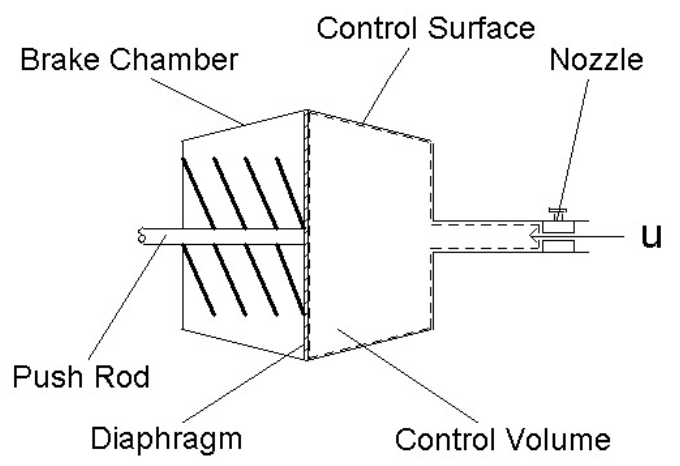

Fig. 7. The brake chamber as the control volume

The term $A_{p}$ is given by the following expression,

$$
A_{p}= \begin{cases}2 \pi r_{p v} x_{p v} & \text { during the apply phase } \\ 2 \pi r_{p p} x_{p p e} & \text { during the exhaust phase }\end{cases}
$$

where $r_{p v}$ is the external radius of the primary valve assembly inlet section and $r_{p p}$ is the 
external radius of the primary piston exhaust seat.

Next, let us consider the mass of air inside the control volume at any instant of time, $m_{b}$. Since we treat air as an ideal gas,

$$
m_{b}=\frac{P_{b} V_{b}}{R T_{b}}
$$

where $P_{b}$ is the local static pressure inside the control volume, $V_{b}$ is the volume of the control volume and $T_{b}$ is the local static temperature inside the control volume at that instant of time.

Differentiating both sides of the above equation with respect to time, we obtain,

$$
\dot{m}_{b}=\frac{\dot{P}_{b} V_{b}}{R T_{b}}+\frac{P_{b} \dot{V}_{b}}{R T_{b}}-\left(\frac{P_{b} V_{b}}{R T_{b}^{2}}\right) \dot{T}_{b}
$$

Using equation (4.44), equation (4.53) can be simplified as,

$$
\dot{m}_{b}=\left(\frac{1}{\gamma}\right) \frac{\dot{P}_{b} V_{b}}{R T_{b}}+\frac{P_{b} \dot{V}_{b}}{R T_{b}}
$$

Let us now consider the variation of the brake chamber volume as a function of time during the brake application. At the start of the application, the brake chamber diaphragm starts to move only after the required "push-out" pressure is reached [12]. This initial increase in pressure is utilized in overcoming the pre-loads of the brake chamber return spring and the return spring in the brake drum. As soon as the push-out pressure is reached, the brake chamber volume starts to increase and as a result, the time rate of growth of the brake chamber pressure decreases. The brake chamber volume reaches its maximum value when the brake pads contact the drum. After this, the time rate of pressure growth starts to increase and the subsequent growth of the brake chamber pressure is utilized in increasing the brake force. These variations are taken into account in our model by varying the expression for the brake chamber volume depending on the phase of operation of the 
brake chamber diaphragm. The volume of air inside the control volume at any instant of time can be written as,

$$
V_{b}= \begin{cases}V_{o 1} & \text { if } P_{b}<P_{t} \\ V_{o 1}+A_{b} x_{b} & \text { if } 0 \leq x_{b}<x_{b \max } \\ V_{o 2} & \text { if } x_{b}=x_{b \max }\end{cases}
$$

where $V_{o 1}$ is the initial volume of air in the control volume before the application of the brake, $V_{o 2}$ is the maximum volume of air in the control volume, $A_{b}$ is the cross-sectional area of the brake chamber, $x_{b}$ is the stroke of the brake chamber diaphragm, i.e., the stroke of the push rod, $x_{b m a x}$ is the maximum stroke of the push rod and $P_{t}$ is the push-out pressure.

Using the above equation, equation (4.54) can be written as,

$$
\dot{m}_{b}= \begin{cases}\left(\frac{V_{o 1}}{\gamma R T_{b}}\right) \dot{P}_{b} & \text { if } P_{b}<P_{t} \\ \left(\frac{V_{b}}{\gamma R T_{b}}\right) \dot{P}_{b}+\left(\frac{P_{b} A_{b}}{R T_{b}}\right) \dot{x}_{b} & \text { if } 0 \leq x_{b}<x_{b \max } \\ \left(\frac{V_{o 2}}{\gamma R T_{b}}\right) \dot{P}_{b} & \text { if } x_{b}=x_{b \max }\end{cases}
$$

Let us now consider the dynamics of the brake chamber (refer to Fig. 8). The equation of motion of the brake chamber diaphragm can be written as (we neglect any friction in the brake chamber), 


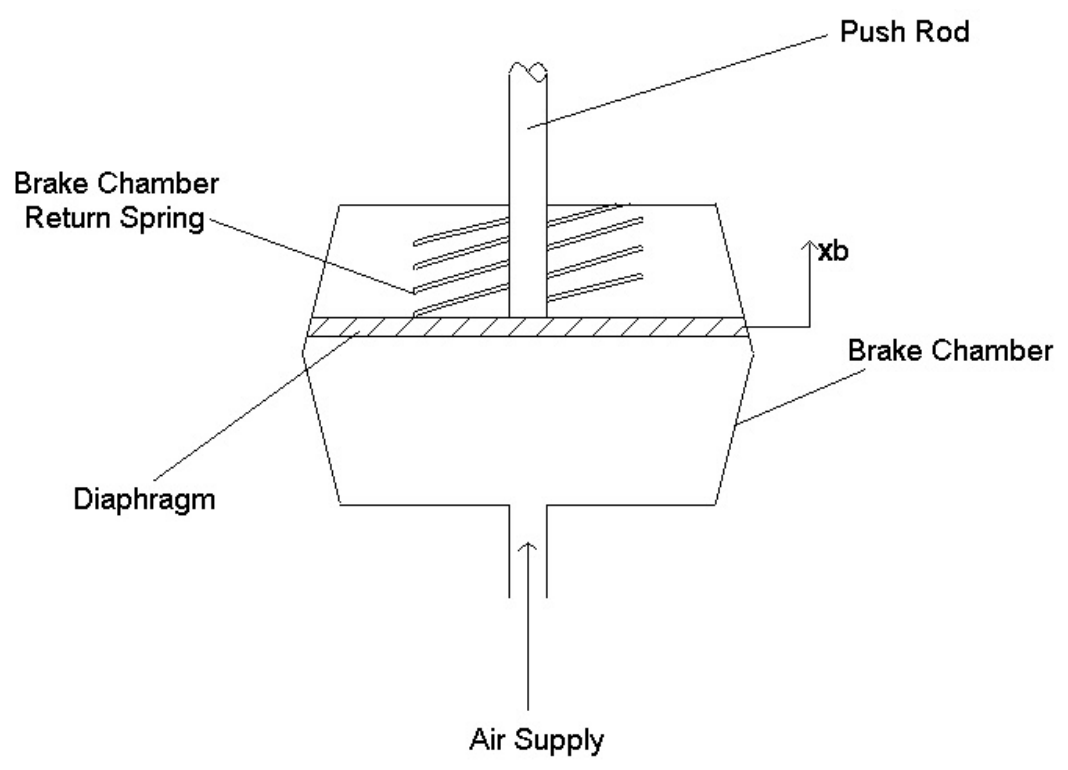

Fig. 8. A sectional view of the brake chamber

$$
M_{b}\left(\frac{d^{2} x_{b}}{d t^{2}}\right)+K_{b} x_{b}=\left(P_{b}-P_{a t m}\right) A_{b}-F_{k b i}
$$

where $M_{b}$ is the mass of the brake chamber diaphragm, $K_{b}$ is the spring constant of the brake chamber return spring and $F_{k b i}$ is the pre-load in the brake chamber diaphragm return spring.

We make an additional simplification by neglecting the inertia of the brake chamber diaphragm. Thus, the above equation reduces to,

$$
x_{b}=\frac{\left(P_{b}-P_{a t m}\right) A_{b}-F_{k b i}}{K_{b}}
$$

Using (4.58) in the equation (4.56), and simplifying yields, 


$$
\dot{m}_{b}= \begin{cases}\left(\frac{V_{o 1}}{\gamma R T_{b}}\right) \dot{P}_{b} & \text { if } P_{b}<P_{t} \\ \left(\frac{V_{b}}{\gamma R T_{b}}+\frac{P_{b} A_{b}^{2}}{R T_{b} K_{b}}\right) \dot{P}_{b} & \text { if } 0 \leq x_{b}<x_{b \max } \\ \left(\frac{V_{o 2}}{\gamma R T_{b}}\right) \dot{P}_{b} & \text { if } x_{b}=x_{b \max }\end{cases}
$$

Equation (4.48) gave us a relationship to calculate the velocity of air at the exit section of the nozzle. We modify this equation with a discharge coefficient $C_{D}$ in order to compensate for the losses during the flow. Due to the complexity involved in calibrating the valve to determine the value of the discharge coefficient, we assumed a value of 0.82 for $C_{D}$ as recommended in [2]. Also, we modify the equation so that the direction of the flow is incorporated.

$$
u=C_{D}\left(\left(\frac{2 \gamma}{\gamma-1}\right) \frac{P_{o}}{\rho_{o}}\left|\left[1-\left(\frac{P_{b}}{P_{o}}\right)^{\left(\frac{\gamma-1}{\gamma}\right)}\right]\right|\right)^{\frac{1}{2}} \operatorname{sgn}\left(P_{o}-P_{b}\right)
$$

The signum function used in the above equation is defined as,

$$
\operatorname{sgn}\left(P_{o}-P_{b}\right):=\frac{P_{o}-P_{b}}{\left|P_{o}-P_{b}\right|}
$$

Thus, the signum function indicates the direction of flow depending on the pressure difference. During the apply and the hold phases, $P_{o}$ is the supply pressure and during the exhaust phase, $P_{o}$ is the atmospheric pressure.

Now using equations (4.42) and (4.60), equation (4.50) can be re-written as, 


$$
\dot{m}_{b}=\frac{P_{b}}{R T_{b}} A_{p} C_{D}\left(\left(\frac{2 \gamma}{\gamma-1}\right) \frac{P_{o}}{\rho_{o}}\left|\left[1-\left(\frac{P_{b}}{P_{o}}\right)^{\left(\frac{\gamma-1}{\gamma}\right)}\right]\right|\right)^{\frac{1}{2}} \operatorname{sgn}\left(P_{o}-P_{b}\right)
$$

When the pressure ratio is less than the critical value, choked flow conditions are assumed and the mass flow rate is maximum through the nozzle under this condition. The critical pressure ratio is given by,

$$
\left(\frac{P_{b}}{P_{o}}\right)_{c r}=\left(\frac{2}{\gamma+1}\right)^{\left(\frac{\gamma}{\gamma-1}\right)}
$$

Now, comparing equations (4.59) and (4.62), we obtain the governing equation for the pressure transients in the brake chamber for the various phases of the motion of the brake chamber diaphragm.

$$
\begin{aligned}
\left(\frac { A _ { p } C _ { D } } { R T _ { b } } \left(\left(\frac{2 \gamma}{\gamma-1}\right) \frac{P_{o}}{\rho_{o}} \mid\left[1-\left(\frac{P_{b}}{P_{o}}\right)^{\left.\left.\left.\left(\frac{\gamma-1}{\gamma}\right)\right] \mid\right)^{\frac{1}{2}} \operatorname{sgn}\left(P_{o}-P_{b}\right)\right) P_{b}=}\right.\right.\right. \\
\begin{cases}\left(\frac{V_{o 1}}{\gamma R T_{b}}\right) \dot{P}_{b} & \text { if } P_{b}<P_{t} \\
\left(\frac{V_{b}}{\gamma R T_{b}}+\frac{P_{b} A_{b}^{2}}{R T_{b} K_{b}}\right) \dot{P}_{b} & \text { if } 0 \leq x_{b}<x_{b \max } \\
\left(\frac{V_{o 2}}{\gamma R T_{b}}\right) \dot{P}_{b} & \text { if } x_{b}=x_{b \max }\end{cases}
\end{aligned}
$$

This is a first order non-linear differential equation in $P_{b}$. Next, we simplify the above equation by using equations (4.42) and (4.44) to obtain the following equation, 


$$
\begin{aligned}
& \left(A_{p} C_{D}\left(\left(\frac{2 \gamma}{\gamma-1}\right) \frac{1}{R T_{o}}\left|\left[\left(\frac{P_{b}}{P_{o}}\right)^{\left(\frac{2}{\gamma}\right)}-\left(\frac{P_{b}}{P_{o}}\right)^{\left(\frac{\gamma+1}{\gamma}\right)}\right]\right|\right)^{\frac{1}{2}} \operatorname{sgn}\left(P_{o}-P_{b}\right)\right) P_{o}=
\end{aligned}
$$

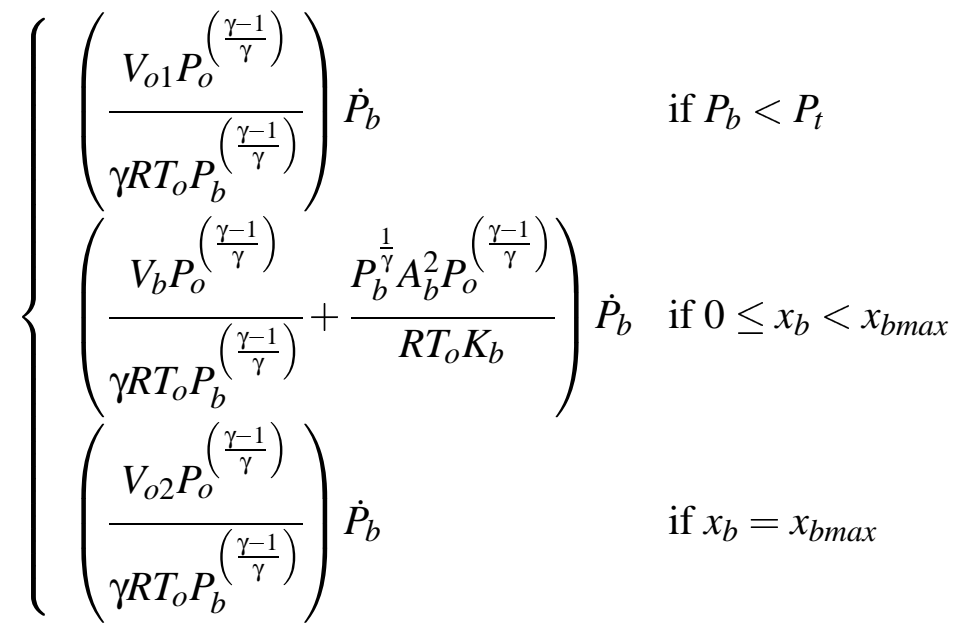

This is the governing equation for the pressure transients in the brake chamber during the apply phase with the term $P_{o}$ being the supply pressure. The coefficients of the above equation are now functions of $P_{b}$ and $A_{p}$ and this equation has to be solved with the initial condition that at the start of the apply phase, $P_{b}=P_{a t m}$. At each time step during the apply phase, the value of the pressure obtained from this equation is used to determine the stage of operation of the two circuits through equations (4.15) and (4.35).

Using equation (4.63), the expression on the left hand side of equation (4.65) can be written as the following, 


$$
f\left(P_{b}, A_{p}\right)=\left\{\begin{array}{l}
\left(\left(\frac{2 \gamma}{\gamma-1}\right) \frac{1}{R T_{o}}\left|\left[\left(\frac{P_{b}}{P_{o}}\right)^{\left(\frac{2}{\gamma}\right)}-\left(\frac{P_{b}}{P_{o}}\right)^{\left(\frac{\gamma+1}{\gamma}\right)}\right]\right|\right)^{\frac{1}{2}} \operatorname{sgn}\left(P_{o}-P_{b}\right) \\
\text { if } \frac{P_{b}}{P_{o}}>\left(\frac{P_{b}}{P_{o}}\right)_{c r} \\
\left.A_{p} C_{D} P_{o}\left(\frac{2 \gamma}{\gamma+1}\right) \frac{1}{R T_{o}}\left(\frac{2}{\gamma+1}\right)^{\left(\frac{2}{\gamma-1}\right)}\right)^{\frac{1}{2}} \operatorname{sgn}\left(P_{o}-P_{b}\right) \\
\text { if } \frac{P_{b}}{P_{o}} \leq\left(\frac{P_{b}}{P_{o}}\right)_{c r}
\end{array}\right.
$$

where $f\left(P_{b}, A_{p}\right)$ refers to the left hand side of equation (4.65).

For the exhaust phase, the term $P_{o}$ is taken to be the atmospheric pressure $P_{a t m}$ and the term $T_{o}$ is taken to be the atmospheric temperature. The governing differential equation is solved with the initial condition that at the start of the exhaust phase, the pressure in the brake chamber is the steady state pressure at the end of the apply phase. The brake chamber volume is the maximum at the start of the exhaust phase and decreases as the exhaust phase progresses according to the following equation,

$$
V_{b}= \begin{cases}V_{o 2} & \text { if } x_{b e}=0 \\ V_{o 2}-A_{b} x_{b e} & \text { if } 0 \leq x_{b e}<x_{b \max } \\ V_{o 1} & \text { if } x_{b e}=x_{b \max }\end{cases}
$$

where $x_{b e}$ is the displacement of the brake chamber diaphragm from its equilibrium position 
at the start of the exhaust phase. 


\section{CHAPTER V}

\section{CORROBORATION OF THE MODEL}

In this chapter, we corroborate the model for the operation of the primary circuit. Equation (4.65) was solved numerically using the fourth order Runge-Kutta method. A time step of 0.0001 seconds was used. Experiments were conducted at various supply pressures and the brake was applied using the actuator. Equation (4.15) was used to determine the start and the termination of the simulation. The simulation for the apply phase was started when the value of $x_{p v}$ became greater than zero which corresponds to the opening of the treadle valve. Two conditions determine the termination of the apply phase - the value of $x_{p v}$ becoming less than or equal to zero (which corresponds to the closure of the valve) and the brake chamber pressure becoming equal to the supply pressure. The simulation ends when either one of these two conditions is satisfied. The inputs to the simulation are the pedal force $F_{p}$ and the plunger displacement $x_{p}$. The parameters used in the simulation were measured and the values of the parameters are tabulated in Table (I). The results are shown from Fig. 9 to Fig. 11.

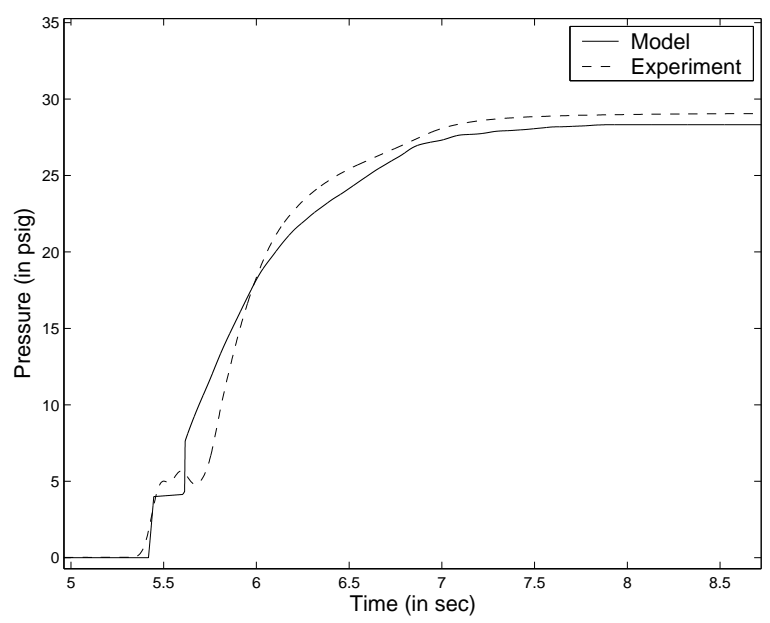

Fig. 9. Pressure transients at 60 psig supply pressure - apply phase 
Table I. Values of the parameters used in the simulation

\begin{tabular}{|c|c|c|c|}
\hline Parameter & Value & Parameter & Value \\
\hline$A_{p v}$ & $0.0002356 \mathrm{~m}^{2}$ & $A_{p v 1}$ & $0.0004184 m^{2}$ \\
\hline$A_{p p}$ & $0.002357 \mathrm{~m}^{2}$ & $A_{b}$ & $0.129 \mathrm{~m}^{2}$ \\
\hline$A_{r p}$ & $0.001985 \mathrm{~m}^{2}$ & $A_{r p}^{\prime}$ & $0.003141 \mathrm{~m}^{2}$ \\
\hline$K_{b}$ & $1167.454 \frac{N}{m}$ & $K_{S S}$ & $2556.724 \frac{N}{m}$ \\
\hline$F_{1}$ & $-193.832 N$ & $K_{2}$ & $8178.716 \frac{N}{m}$ \\
\hline$L_{1}$ & $68.944 N$ & $L_{2}$ & $6418.078 \frac{N}{m}$ \\
\hline$x_{p t}$ & $0.00127 \mathrm{~m}$ & $P_{a t m}$ & 101.356 KPa \\
\hline$r_{p v}$ & $0.01283 \mathrm{~m}$ & $r_{p p}$ & $0.01232 \mathrm{~m}$ \\
\hline$\gamma$ & 1.4 & $V_{o 1}$ & $0.0001639 \mathrm{~m}^{3}$ \\
\hline$x_{b \max }$ & $0.0254 m$ & $F_{k b i}$ & $355.84 N$ \\
\hline$R$ & $287 \frac{J}{k g K}$ & $T_{o}$ & $298 K$ \\
\hline$C_{D}$ & 0.82 & & \\
\hline
\end{tabular}




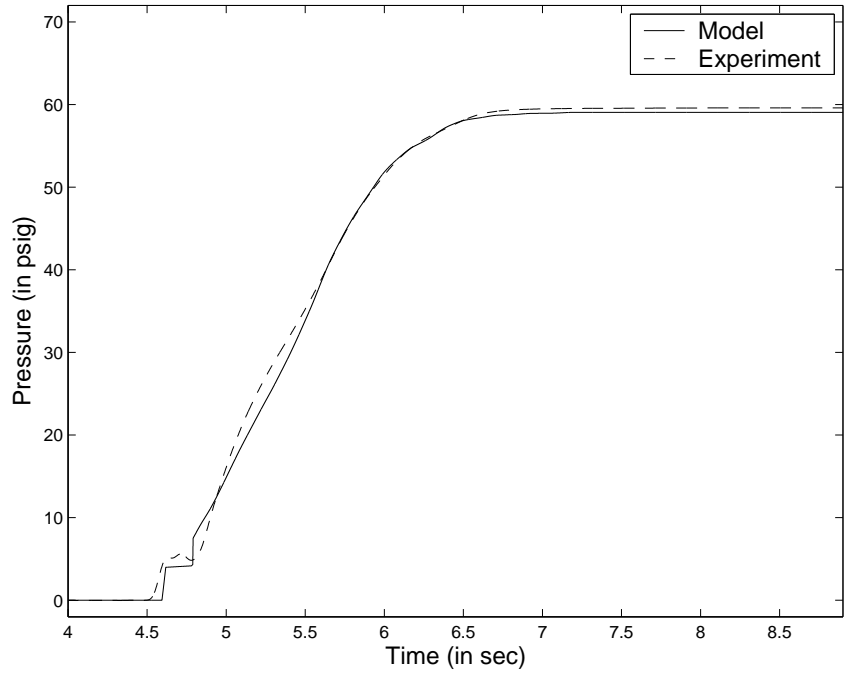

Fig. 10. Pressure transients at 80 psig supply pressure - apply phase

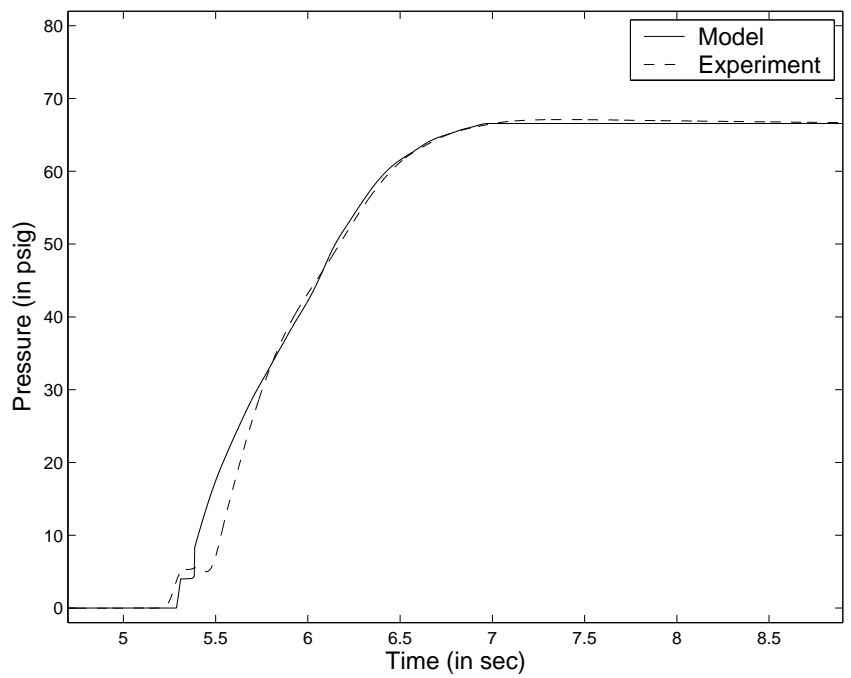

Fig. 11. Pressure transients at 90 psig supply pressure - apply phase 


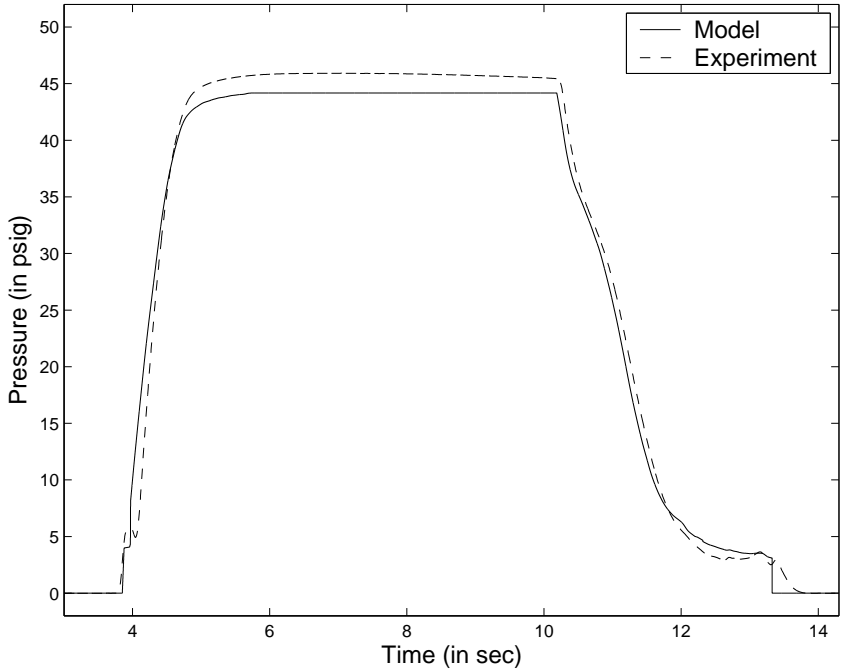

Fig. 12. Pressure transients at 70 psig supply pressure - apply and exhaust phases

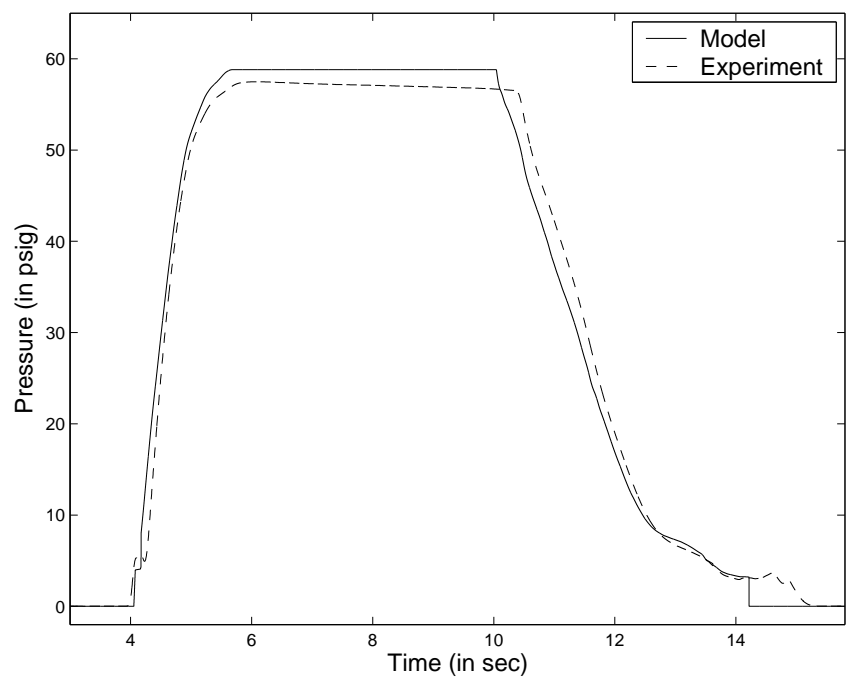

Fig. 13. Pressure transients at 80 psig supply pressure - apply and exhaust phases 


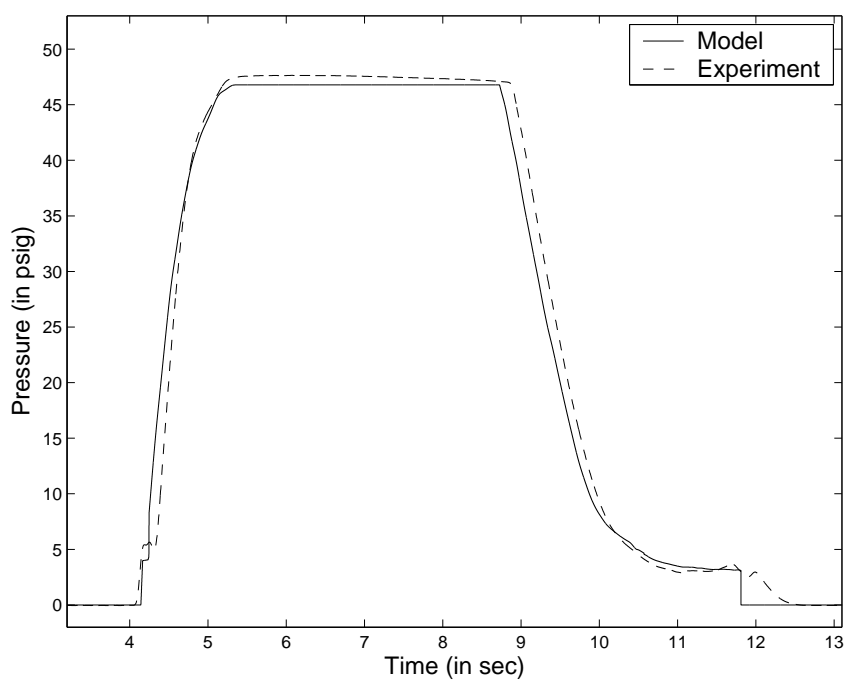

Fig. 14. Pressure transients at 90 psig supply pressure - apply and exhaust phases

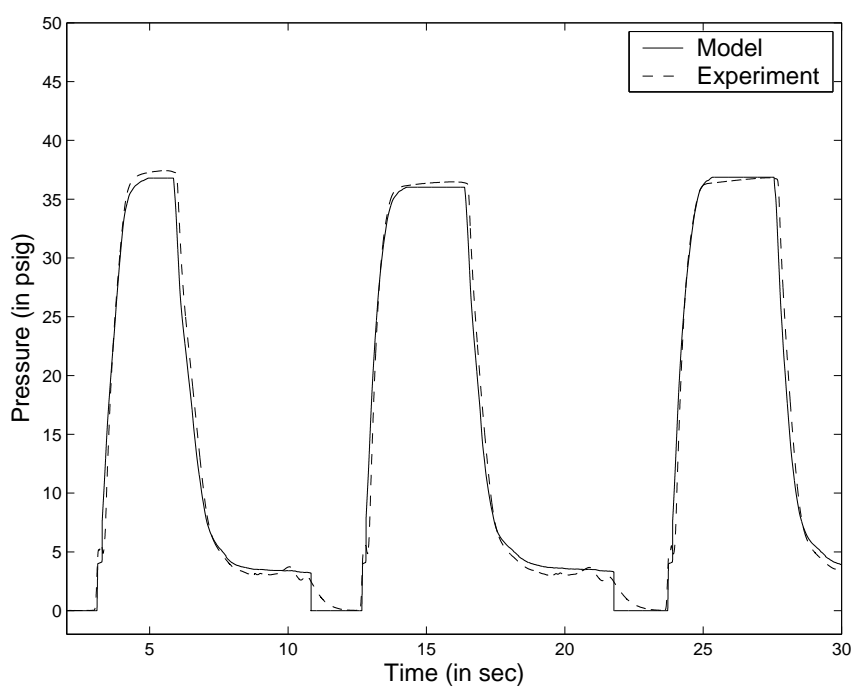

Fig. 15. Pressure transients at 70 psig supply pressure - periodic application 
We can observe from Fig. 9 to Fig. 11 that the model is able to predict the start and the end of the brake application for all the cases. The steady state value of the brake chamber pressure is also predicted accurately. We can also observe that the model is able to follow the initial behavior of the pressure growth curve since we divided the operation of the brake chamber into three different phases.

Tests were also performed for a complete cycle of brake application. The model was used to simulate both the apply and the exhaust phases for such applications. The results are shown from Fig. 12 to Fig. 14. Finally, a test run was performed where the apply and the exhaust phases were periodically repeated. Results from such a test run is shown in Fig. 15. 


\section{CHAPTER VI}

\section{CONCLUDING REMARKS AND FUTURE WORK}

From the above figures, it can be seen that the model was able to predict the beginning and the end of each brake application accurately. The steady state values are also accurately predicted by the model in all the cases. We observe that the model responded well to various supply pressures. The model also predicted the start and the termination of the exhaust phase accurately as was evident from Fig. 12 to Fig. 14. Fig. 15 demonstrated that the model responds well to periodic applications of the brake pedal.

With this model of the pneumatic subsystem of the air brake system, current work is directed towards estimating the stroke of the push rod. An estimation scheme is being developed that will estimate the push rod stroke from measurements of the pedal displacement and the pedal force. Experiments are being performed to measure the push rod stroke during the brake application and the results from the estimation scheme would be corroborated with these measurements. 


\section{REFERENCES}

[1] T. Acarman, U. Ozguner, C. Hatipoglu and A. M. Igusky, "Pneumatic brake system modeling for systems analysis," SAE Paper 2000-01-3414, 2000.

[2] B. W. Anderson, The Analysis and Design of Pneumatic Systems, New York: John Wiley \& Sons, Inc., 1967.

[3] R. M. Braswell, J. F. Broder, P. J. Fisher, R. D. Flesher, D. Foster, S. Gooch, K. F. Johnson, H. T. Pannella, R. L. Rak, G. H. Rood, J. Salas, C. O. Summer, V. Suski and J. Thrift, "Tomorrow's trucks: A progress review and reappraisal of future needs," SAE Paper 932975, 1993.

[4] L. C. Buckman, "Commercial vehicle braking systems: Air brakes, ABS and beyond," paper presented at International Truck \& Bus Meeting \& Exposition, Society of Automotive Engineers, Indianapolis, November 1998.

[5] M. Druzhinina, L. Moklegaard and A. G. Stefanopoulou, "Identification and integration of commercial heavy vehicle retarders," Research Report UCB-ITS-PRR-200214, California PATH Program, University of California, Berkeley, California, March 2002.

[6] J. C. Gerdes and J. K. Hedrick, "Brake system modeling for simulation and control," Journal of Dynamic Systems, Measurement and Control, vol. 121, pp. 496-503, September 1999.

[7] "Inspection statistics," http://www.ntsb.gov/publictn/2002/SR0201.pdf, 2003 [Accessed January 2003]. 
[8] L. Johnson, P. S. Fancher and T. D. Gillespie, "An empirical model for the prediction of the torque output of commercial vehicle air brakes," Research Report UMHSRI-78-53, Highway Safety Research Institute, University of Michigan, Ann Arbor, Michigan, December 1978.

[9] Y. Khan, P. Kulkarni and K. Youcef-Toumi, "Modeling, experimentation and simulation of a brake apply system," Journal of Dynamic Systems, Measurement and Control, vol. 116, pp. 111-122, March 1994.

[10] H. W. Liepmann and A. Roshko, Elements of Gasdynamics, Mineola, New York: Dover Publications, Inc., 2001.

[11] D. Middleton and J. Rowe, "Feasibility of standardized diagnostic device for maintenance and inspection of commercial motor vehicles," Transportation Research Record, vol. 1560, pp. 48-56, 1996.

[12] R. J. Morse, "Brake system performance at low operating pressures," SAE Paper $700512,1970$.

[13] K. Newton, W. Steeds and T. K. Garrett, The Motor Vehicle, 12th edition, Warrendale, Pennsylvania: Society of Automotive Engineers, Inc., 1996.

[14] A. V. Oppenheim and R. W. Schafer, Digital Signal Processing, Englewood Cliffs, New Jersey: Prentice-Hall, Inc., 1975.

[15] T. M. Post, P. S. Fancher and J. E. Bernard, "Torque characteristics of commercial vehicle brakes," SAE Paper 750210, 1975.

[16] R. W. Radlinski, "Braking performance of heavy U.S. vehicles," SAE Paper 870492 , 1987. 
[17] R. W. Radlinski, "Heavy vehicle braking - U.S. versus Europe," SAE Paper 892504, 1989.

[18] P. G. Reinhall and R. R. Scheibe, "Development of an intelligent air brake warning system for commercial vehicles," Research Report ITS-13, IDEA Program, Transportation Research Board, National Research Council, Washington, D.C., May 1996.

[19] S. J. Shaffer and G. H. Alexander, "Commercial vehicle brake testing - Part 1: Visual inspection versus performance-based test," SAE Paper 952671, 1995.

[20] S. J. Shaffer and G. H. Alexander, "Commercial vehicle brake testing - Part 2: Preliminary results of performance-based test program," SAE Paper 952672, 1995.

[21] G. W. Stearns, "FMVSS 121 - Air brake systems: How it affects tractor-trailer combinations," Automotive Engineering, vol. 81, pp. 37-48, September 1973.

[22] "TIFA statistics," http://www.umtri.umich.edu/cnts/doc/TIFA1999.pdf, 2003 [Accessed January 2003].

[23] S. F. Williams and R. R. Knipling, "Automatic slack adjusters for heavy vehicle air brake systems," Research Report DOT HS 807 724, National Highway Traffic Safety Administration, Washington, D.C., February 1991.

[24] M. J. Zucrow and J. D. Hoffman, Gas Dynamics, vol. 1, New York: John Wiley \& Sons, Inc., 1976. 
VITA

Shankar Coimbatore Subramanian was born in the city of Coimbatore, located in the Indian state of Tamilnadu. He was brought up in the city of Chennai and completed high school there. He obtained his Bachelor of Engineering in mechanical engineering from the University of Allahabad in May 2000. He joined the Mechanical Engineering Department at Texas A\&M University in August 2000. He graduated with a Master of Science degree in mechanical engineering from Texas A\&M University in May 2003. Shankar Coimbatore Subramanian may be contacted through Prof. K. R. Rajagopal at the Department of Mechanical Engineering, Texas A\&M University, College Station, TX 77843-3123. 